\title{
A avaliação orientando as estratégias do ciclo em uma escola pública do Distrito Federal
}

\author{
Evaluation guiding cycle strategies in a public school in the Distrito Federal
}

Gilcéia Leite dos Santos Fontenele ${ }^{1}$

\begin{abstract}
RESUMO
Este estudo está ligado à minha dissertação de mestrado intitulada: "A avaliação no $3^{\circ}$ ciclo e suas implicações no trabalho pedagógico de uma escola pública do Distrito Federal", defendida em 2019. O seu objetivo consiste em analisar em que medida a avaliação para as aprendizagens vem orientando as estratégias pedagógicas em uma escola organizada em ciclos no Distrito Federal. A metodologia é a qualitativa e a perspectiva é a crítico-dialética. Nos procedimentos e instrumentos estão a análise documental; entrevistas semiestruturadas; grupos focais e observações. As análises das narrativas contaram com os núcleos de significação de acordo com Aguiar e Ozella (2006, 2013). A pesquisa revelou que o processo avaliativo vem orientando o trabalho pedagógico na escola pesquisada, além disso, indicou a importância da coordenação pedagógica, do planejamento articulado e da atuação do colegiado escolar no e para o desenvolvimento das práticas avaliativas que favoreçam a superação das dificuldades surgidas no decorrer do ensino-aprendizagem.
\end{abstract}

Palavras-chave: Organização escolar em ciclos; Avaliação; Trabalho pedagógico.

\begin{abstract}
This study is linked to my master's thesis entitled: "Assessment in the 3rd cycle and its implications for the pedagogical work of a public school in the Distrito Federal", defended in 2019. Its objective is to analyze the extent to which assessment for learning has been guiding the pedagogical strategies in a school organized in cycles in the Distrito Federal. The methodology is qualitative and the perspective is criticaldialectical. The procedures and instruments include document analysis; semi-structured interviews; focus groups and observations. The analysis of the narratives relied on the meaning cores according to Aguiar and Ozella $(2006,2013)$. The research revealed that the evaluation process has been guiding the pedagogical work in the researched school, in addition, it indicated the importance of pedagogical coordination, articulated planning and the performance of the school collegiate in and for the development of evaluation practices that favor the overcoming of the difficulties that have arisen. during the teaching-learning process.
\end{abstract}

Keywords: School organization in cycles; Evaluation; Pedagogical work.

1 Especialista em Administração da Educação, em Psicopedagogia Clínica e Institucional e em Coordenação Pedagógica. Mestre em Educação pela Universidade de Brasília e professora da Secretaria de Estado de Educação do Distrito Federal - SEEDF. E-mail: gilceia.fontenele@gmail.com. 


\section{INTRODUÇÃO}

A minha experiência como professora da escola básica me instigou e me despertou para o estudo da avaliação para as aprendizagens, por acreditar que o ato avaliativo permeia todas as ações pedagógicas escolares, sendo, desta forma, um processo que funciona como um termômetro para a organização do trabalho realizado na escola como um todo e na sala de aula.

Assim, apresento o questionamento deste estudo: em que medida a avaliação para as aprendizagens vem orientando as estratégias pedagógicas em uma escola organizada em ciclos no Distrito Federal? A partir desta indagação propus o seguinte objetivo: analisar em que medida a avaliação para as aprendizagens vem orientando as estratégias pedagógicas em uma escola organizada em ciclos no Distrito Federal. Desta forma, busquei entender como a avaliação para as aprendizagens estava colaborando com a organização do trabalho pedagógico em uma escola que implementava os ciclos.

A abordagem dessa pesquisa é a qualitativa, a qual "tem o ambiente natural como sua fonte direta de dados e o pesquisador como seu principal instrumento" (LÜDKE; ANDRÉ, 1986, p. 11) quanto ao tipo é o estudo de caso (idem).

Os pressupostos metodológicos são propostos por Gamboa (2006) com base em três categorias: epistemológica, gnosiológica e ontológica, articulando teoria e prática em uma perspectiva crítico-dialética. A análise das narrativas contou com os núcleos de significação, de acordo com Aguiar e Ozella (2006, 2013).

\section{A AVALIAÇÃO ORIENTANDO AS ESTRATÉGIAS DO CICLO}

Por ser intencional, a ação educativa necessita do planejamento, com o objetivo de discutir, refletir e sistematizar o trabalho pedagógico e favorecer as tomadas de decisões, a estruturação de atividades, o bom funcionamento da escola, o desenvolvimento de ensino-aprendizagem. (SILVA, E. 2017a).

O planejamento envolve a dimensão técnica e define objetivos, conteúdos, procedimentos, recursos e avaliação, abrange, também, a dimensão política e pedagógica, 
que pode favorecer a articulação dos condicionantes histórico-sociais, dos conhecimentos e das experiências prévias dos estudantes. O planejamento, também, envolve três níveis: o macro desenvolvido pelos governos federal, estadual e municipal: o meso, realizado pelas regionais de ensino, pelas coordenações e pelas delegacias de ensino e o micro, que envolve a escola e a sala de aula (idem). Silva, E. (2017a) destaca, porém, que está, no planejamento coletivo, a melhor intenção para organizar e desenvolver um trabalho pedagógico coerente com os objetivos das redes de ensino e com o projeto políticopedagógico da escola.

Quanto ao planejamento do trabalho pedagógico desenvolvido na escola e na sala de aula e à utilização das coordenações pedagógicas, o professor Lucas declarou:

nós temos três coordenações semanais, duas, no caso, direcionadas por área e uma coletiva, que envolve todos. Nessas coletivas, por exemplo, a gente direciona o informativo geral da escola. (Professor Lucas - Geografia).

A partir das falas do professor Lucas, é possível perceber que as coordenações coletivas estão mais voltadas para o repasse de informações do que para o planejamento coletivo. Essa situação revela a necessidade de as coordenações coletivas serem revistas como espaço de planejamento colaborativo, nas quais o trabalho pedagógico poderá ser pensado em conjunto e favorecer, então, uma nova organização do trabalho escolar. Nesse sentido, Silva, E. (2017a) orienta sobre a importância do planejamento, pois a ação de planejar proporciona o alcance dos objetivos, da intencionalidade do projeto políticopedagógico e o desenvolvimento do currículo.

No entanto, o professor Lucas lembrou que,

nas coordenações por área, é onde a gente determina, junto com os colegas de Geografia e História, mais ou menos, aquilo que a gente vai trabalhar, tendo que conciliar os conteúdos, de forma a aproveitar o que o professor de História está dando, para ficar, mais ou menos, dentro do mesmo contexto. (Professor Lucas - Geografia).

Lucas enfatizou que a organização do seu trabalho pedagógico é realizada durante a semana, quando ele se reúne com o professor de História, procurando realizar um planejamento integrado. Nessa direção, as Diretrizes Pedagógicas para a Organização Escolar do $3^{\circ}$ Ciclo orientam que a coordenação pedagógica deverá ser o espaço primordial para a organização do trabalho pedagógico, o qual deverá ser desenvolvido de maneira colaborativa e envolver a equipe escolar (DISTRITO FEDERAL, 2014b). Araújo (2000, p. 119) salienta que “a coordenação pedagógica constitui-se como uma das maiores possibilidades de organização do trabalho pedagógico, do planejamento escolar, das decisões pedagógicas", um lugar, onde o pensar e o agir político-pedagógico ocupam 
espaço privilegiado, fomentando a necessidade do trabalho coletivo e a superação do individualismo pedagógico.

A esse respeito, tive a oportunidade de conversar com a professora Eduarda de História sobre a realização da avaliação diagnóstica planejada para a segunda semana de aula de 2018. Perguntei acerca do conteúdo da prova e ela esclareceu que envolvia ortografia, interpretação e escrita de texto, considerando que o aluno que escreve e interpreta bem, seria capaz de atingir os objetivos no componente curricular ministrado por ela. Com o mapeamento, os alunos são agrupados de acordo com os níveis, os quais apresentam os objetivos de aprendizagens, depois desta organização, é realizada a estratégia de reagrupamento.

O reagrupamento tem duas formas no intraclasse (feito dentro da sala de aula e o professor faz essa organização no dia a dia) e tem aquele que é feito no interclasse, que é o que a gente vai fazer agora, no início de outubro. São dois dias, nos quais a gente redistribui os alunos de acordo com os níveis. A gente separa o bloco I ( $6^{\circ}$ e $7^{\circ}$ anos) e bloco II ( $8^{\circ}$ e $9^{\circ}$ anos) e faz o reagrupamento conforme os níveis 1,2 e 3 e reagrupa esses alunos, fazendo uma relocação deles por sala, conforme o nível. Antes, são preparadas atividades para os diferentes níveis de acordo com a complexidade de aprendizagem. Assim, temos: os níveis 1,2 e 3 do bloco I $\left(6^{\circ}\right.$ e $7^{\circ}$ anos) e os níveis 1,2 e 3 do bloco II ( $8^{\circ}$ e $9^{\circ}$ anos). Então, a gente reorganiza toda a escola e prepara uma listagem de alunos para eles saberem, na entrada, a qual nível eles irão e os professores que irão atendê-los. (Coordenadora Marta).

O reagrupamento, descrito pela coordenadora, Marta "é uma estratégia pedagógica que permite agrupar os estudantes de acordo com as dificuldades, a fim de promover o avanço contínuo das aprendizagens" (DISTRITO FEDERAL, 2014b, p. 62). O reagrupamento interclasse envolve a formação de grupos de estudantes a partir de necessidades e potencialidades detectadas, independente do bloco ou do ano em que o aluno esteja matriculado. (DISTRITO FEDERAL, 2014 b).

A despeito do reagrupamento interclasse, as múltiplas determinações sobre o trabalho pedagógico, às vezes, não permitem que os processos aconteçam como planejado, sem percalços. Foi o que ocorreu no segundo semestre letivo, quando a escola não pôde cumprir seu planejamento e realizar o segundo reagrupamento interclasse, previsto para o mês de outubro, conforme o plano de ação elaborado no início do ano letivo. Apesar de o Projeto Político Pedagógico da escola (2018) ressaltar a importância dessa estratégia de reagrupamento, nos $3^{\circ}$ e $4^{\circ}$ bimestres, não presenciei momentos de desenvolvimento dos reagrupamentos e observei que as atividades planejadas nem sempre eram cumpridas, devido a justificativas diversas, como: eventos na escola (Festa 
das Regiões, formaturas, passeios pedagógicos); falta de recursos humanos; atestados médicos; e licenças-maternidade, dentre outras.

Diante desse cenário, pude observar que os eventos realizados na escola, as atividades planejadas pela Coordenação Regional de Ensino, assim como a ausência dos professores podem fragilizar o trabalho coletivo. Na escola, o planejamento foi realizado na coordenação coletiva do dia 12/09/2018, na qual o grupo de professores planejou o reagrupamento interclasse sob o tema feminicídio e, no dia 19/09/2018, foram definidos os procedimentos, mas o reagrupamento não ocorreu no mês previsto (outubro). Nessas condições, com o planejamento não executado, houve descontinuidade e falta de sistematização do trabalho pedagógico.

Essas atividades do reagrupamento interclasse foram desenvolvidas, posteriormente, com os alunos dos $7^{\circ} \mathrm{s}$ e $9^{\circ} \mathrm{s}$ anos que ficaram para a recuperação final ${ }^{2}$. Entretanto, mesmo que o reagrupamento tenha ocorrido, vejo a recuperação final como uma contradição existente nos ciclos, uma herança da organização do trabalho pedagógico seriado, que deveria ser repensada, pois, como afirma Villas Boas (2008, p. 92), "na avaliação formativa [prevista para os ciclos] não cabe falar de recuperação", porque, nesta perspectiva de avaliação, as dificuldades de aprendizagem não deverão ser acumuladas, além disso,

não faz sentido falar em recuperação em um processo de trabalho em que a aprendizagem e a avaliação andam sempre juntas. Se o aluno está em processo permanente de aprendizagem, ele nada tem a recuperar. (VILLAS BOAS, 2012, p. 80).

Nesse sentido, a recuperação nos ciclos deve acontecer ao longo do processo. Para isso ocorrer, existem as estratégias pedagógicas, que poderão ser desenvolvidas, como: projetos interventivos, reagrupamento e outras, previstas nas Diretrizes para a Organização do Trabalho Pedagógico do $3^{\circ}$ Ciclo (2014d), diferente da seriação, em que a recuperação realiza-se, geralmente, para melhorar a nota, com a finalidade de aprovar ou reprovar o estudante (VILLAS BOAS, 2012), práticas, ainda, presentes na escola em ciclos e que são legitimadas pelo próprio Regimento Escolar da Rede Pública de Ensino

\footnotetext{
${ }^{2}$ A recuperação final é prevista pelo Regimento das Escolas Públicas do Distrito Federal (2015) e pode ser realizada após o término do semestre/ano letivo para o estudante que não obteve aproveitamento suficiente em três componentes curriculares, no caso dos ciclos, no $7^{\circ}$ e $9^{\circ}$ anos, nos quais a retenção está prevista. Nos $6^{\circ}$ e $8^{\circ}$ anos não há prova de recuperação final.
} 
do Distrito Federal, que indica, no artigo 215, tanto a recuperação contínua como a final. (DISTRITO FEDERAL, 2015, p. 44).

Seguindo as ideias de Villas Boas (2012), Paro (2003, p. 42) salienta que "a recuperação deveria ser pensada como um princípio da própria avaliação" e deveria se efetivar por meio de um processo contínuo e permanente, que fizesse parte do próprio exercício de ensinar e aprender. Assim, a avaliação diagnosticaria dificuldades e problemas, que a recuperação procuraria resolver. Nesse sentido, a recuperação se dedicaria a "Corrigir o processo", buscando o aprendizado que ainda não aconteceu (PARO, 2003). A pesquisa de Ambrósio (2015) revelou que a recuperação contínua das aprendizagens, apresenta-se como um dos mecanismos essenciais para que os alunos atinjam melhores condições de aprendizado, esse tipo de recuperação se alinha à proposta para os ciclos na Secretaria de Educação do Distrito Federal.

Assim, o Projeto Político Pedagógico da escola (2018), em conformidade a LDBEN (9394/96), ressalta a importância do acompanhamento escolar, com a avaliação contínua dos estudantes e a obrigatoriedade de estudos de recuperação, de preferência, paralelos ao período letivo, quando o baixo rendimento for identificado. As Diretrizes de Avaliação Educacional da SEEDF (2014b), também, destacam a importância da recuperação escolar contínua e a entende como: "a realização de intervenções pedagógicas contínuas com os estudantes, sempre que as necessidades de aprendizagem forem evidenciadas" (DISTRITO FEDERAL, 2014d, p. 39). Estas Diretrizes orientam que a recuperação seja associada à avaliação formativa e compreendendo que aprendizagem é dinâmica, avalia-se o tempo todo, regulando o processo.

Quando os estudantes foram questionados a respeito da sua participação nas estratégias previstas para os ciclos, que favorecem a recuperação das aprendizagens, como, projeto interventivo ou reagrupamentos, 11 dos 15 alunos, disseram que não participavam de nenhuma estratégia e 2 disseram que às vezes participavam: "eu participava dos reagrupamentos da escola, quando estava no $8^{\circ}$ ano". (Estudante Isa $9^{\circ}$ ano "B"). "Eu participo no máximo do reagrupamento, raro na escola". (Estudante Dudu $-7^{\circ}$ ano “A”).

Embora, a coordenadora Marta deixasse entender que todos os alunos participavam do diagnóstico inicial e dos reagrupamentos, os estudantes reforçaram que nem sempre ocorrem os reagrupamentos, como eu observei no período em que estive na escola. 
Os reagrupamentos intraclasse são previstos nas Diretrizes Pedagógicas para a Organização Escolar do $3^{\circ}$ ciclo (2014b), porém, essas estratégias, ocorrem de maneira muito tímida na escola, reduzidas à realização de trabalhos e exercícios em grupos e duplas. Observei 8 aulas com reagrupamento intraclasse nas disciplinas de: Ciências, Geografia, História, Inglês, Matemática e Língua Portuguesa. Em todas elas, os professores propunham atividades no quadro ou utilizavam o livro didático e os grupos, ou as duplas, realizavam as atividades propostas sob a mediação do professor. De acordo com a aluna Nanda, "tem professores que eu não entendo, não consigo entender, aí eu peço ajuda para alguns amigos meus [...] às vezes, com o colega, você aprende melhor do que com o professor [...]" (Estudante Nanda $9^{\circ}$ ano "B").

Complementando o que a Nanda disse, perguntei aos alunos a quem eles recorriam (não podia ser o professor) para ajudar nas tarefas escolares: 7 disseram que não precisavam de ajuda, 2 disseram que, às vezes, precisavam de ajuda, 2 disseram que recorriam a pessoas da família e 4 preferiam contar com a ajuda dos amigos, o que reforça as falas de Nanda de que os estudantes podem se ajudar no processo ensinoaprendizagem.

Além dos reagrupamentos intraclasse e interclasse, as Diretrizes Pedagógicas para a Organização Escolar do $3^{\circ}$ Ciclo preveem o projeto interventivo a ser desenvolvido em quatro momentos: o primeiro deles é observar quem precisa de ajuda e qual a necessidade; o segundo é a elaboração de um projeto; e o terceiro e o quarto momento são o desenvolvimento e a avaliação. Apesar de todos os momentos serem importantes, a avaliação é o fio condutor, por isso deve estar presente em todos os momentos do projeto (DISTRITO FEDERAL, 2014b), pois será, por meio dela, que se saberá os objetivos foram alcançados e se os alunos aprenderam.

Embora, o trabalho pedagógico, ainda, não aconteça de acordo com o previsto nas Diretrizes Pedagógicas para a Organização Escolar do $3^{\circ}$ Ciclo (2014b), a coordenadora Marta demonstra apoiar a proposta dos ciclos por compreender que este tipo de organização escolar favorece as aprendizagens. Segundo ela,

[...] o resgate das aprendizagens é uma proposta interessante de se trabalhar, porque ela realmente está voltada para o desenvolvimento e para a construção dessa aprendizagem. Talvez alguém, ainda, não tinha parado para ver essa questão, como agora nos ciclos, conhecer melhor o aluno, trabalhar com nivelamento, fazer os reagrupamentos. Quando você faz isso, você está, o tempo todo, tentando resgatar a aprendizagem. Eu acho que o ciclo favorece a aprendizagem. (Coordenadora Marta). 
Essa coordenadora acredita que nos ciclos é preciso entender como o aluno aprende e, a partir disso, desenvolver estratégias pedagógicas, visando às aprendizagens e ao proferir as palavras: "quando você faz isso", Marta sugere que a escola não está desenvolvendo os reagrupamentos como deveria.

As narrativas das coordenadoras, dos professores e dos estudantes revelam que não é fácil desenvolver uma avaliação comprometida com o trabalho pedagógico, acompanhando as aprendizagens dos estudantes no $3^{\circ}$ ciclo. Um dos obstáculos para que isso aconteça são os vários níveis de desempenho em sala de aula, mas o professor poderá compartilhar o papel de mediador com seus alunos, os quais agirão sob o planejamento e a supervisão docente, objetivando-se o atendimento das necessidades de aprendizagem, como foi sugerido pela aluna Nanda.

Nessas condições, os alunos terão a oportunidade de auxiliar seus colegas por meio de um trabalho cooperativo e ao mesmo tempo em que, aprendem, uma vez que ensinar é, também, uma maneira de aprender (DURAN, 2008). Essa parceria com os estudantes ajuda o professor e sinaliza que ele abre mão de sua posição magistrocêntrica. Diante disso, Duran (2008) salienta que

quando o professor reserva o monopólio do papel de mediador e ao se colocar isoladamente a ajudar a ensinar a todos e a cada um dos seus alunos, verifica que não "atinge" todos eles e se vê pressionado por não poder atendê-los individualmente, observá-los e avaliá-los. (p. 14) (Grifos do autor).

Reforçando as reflexões apresentadas de Duran (2008), a professora Eduarda busca alternativas para acompanhar seus alunos, procurando melhor atendê-los e prefere contar com a ajuda deles:

o aluno que está melhor, o que está saindo-se bem, pode ajudar o outro que está mais fraquinho. Eu trabalho muito com o nivelamento da turma, eu tenho 280 alunos nos $7^{\circ}$ s anos e 90 alunos nos $9^{\circ}$ s anos. Tenho umas 10 turmas com 35 alunos. Essa avaliação você tem até que nivelar para você trabalhar, se não nivelar você não consegue fazer um bom trabalho. Então, eu tenho alunos de nível 1, 2 e 3, dentro de uma turma só [...] Um aluno que você pode exigir mais, que está adiantado, que pode estar me dando retorno maior na avaliação, eu utilizo este aluno na monitoria, se não, não tem como trabalhar e avaliar direito. (Professora Eduarda - História).

As aulas da Eduarda são dinâmicas e levam o aluno a pensar e a aprender. A professora constrói com eles o aprendizado, como ela mesma disse:

às vezes, eu até antecipo um tema da minha aula, por exemplo, vou dar aula na semana que vem, então, eu antecipo o tema. Aí o aluno mais curioso vai para a internet e pesquisa o tema. Aí, quando ele vem, ele vem prontinho; ele é um aluno participativo, um aluno que desafia até o meu conhecimento. Eu gosto dessa experiência, dessa troca. (Professora Eduarda - História). 
às Vezes, eu monto a aula na hora, junto com o que o aluno trouxe, da sua experiência, com o que ele pesquisou antes. Aí, o que eu faço no meu relatório, eu já estou avaliando aquele aluno proativo. Adoro fazer minha aula com o que eles vão falando, eu vou desenvolvendo. Aí eu pesquisei isso aqui, assim, assim [...] a gente formula o conceito, um debate, com o auxílio do livro e da experiência que eles vão trazendo. (Professora Eduarda - História).

O ensinar avaliando da professora Eduarda remete a Loch (2008), a qual defende que a avaliação não é para dar notas, conceitos ou pareceres descritivos, mas para garantir as aprendizagens. Nesse sentido, o professor pode agir, favorecendo a construção de um novo conhecimento por meio de uma avaliação, que permita ver o estudante, individualmente, apreendendo o que ele sabe e o que está construindo e, a partir daí, planejar intervenções, visando ao avanço das aprendizagens.

No grupo focal realizado com o $9^{\circ}$ ano "B", os alunos destacaram que a professora Eduarda é uma das docentes que melhor ensina e avalia:

a professora de História, eu gosto muito dela, porque ela é uma das melhores professoras, porque ela consegue ensinar divertindo, brincando, assim, a gente aprende mais, eu acho a aula dela muito boa. (Estudante Leo $-7^{\circ}$ ano "A”).

Os demais alunos presentes concordaram e reforçaram a fala do Leo.

As aulas divertidas da professora Eduarda, remetem às Diretrizes Pedagógicas para Organização Escolar do $3^{\circ} \mathrm{Ciclo,} \mathrm{as} \mathrm{quais} \mathrm{propõem} \mathrm{a} \mathrm{ludicidade} \mathrm{e} \mathrm{os} \mathrm{letramentos}$ como eixos integradores. Nesse caso o eixo é entendido como algo que integra e está o tempo todo presente no trabalho pedagógico da escola em ciclos e, quando articulados entre si e com os objetivos e conteúdos curriculares, poderão favorecer a proficiência leitora e escritora dos educandos. (DISTRITO FEDERAL, 2014b).

O aluno Dudu, disse que "a professora de Matemática explica muito bem. Quando um aluno pergunta, ela vem e responde para todos escutarem, aí quem estava com dúvidas guardadas, aprende." (Estudante Dudu - 7 ano “A”).

A professora Lívia é outra professora, cujo trabalho pedagógico apresenta um diferencial, porque ela consegue articular a avaliação ao trabalho pedagógico, suas aulas são guiadas pelas aprendizagens dos alunos. Lívia desenvolveu uma técnica de utilização do quadro com seus alunos muito interessante: depois que realizam as atividades no caderno e a professora corrige, ela pede que um aluno se voluntarie para ir ao quadro resolver o exercício, quem diz se ele acertou são os próprios estudantes. Caso haja acerto, ele explica a questão para os colegas com a ajuda da professora, se houver erro, outro estudante vai ao quadro para resolver a questão, até que alguém acerte. 
Durante as observações que realizei no $7^{\circ}$ ano "A", foi possível perceber, que, desenvolvendo o trabalho pedagógico com a participação dos alunos, a professora conseguia despertar o desejo de aprender Matemática e mantinha a turma sempre motivada.

\section{CONSIDERAÇÕES FINAIS}

O objetivo desse estudo consistiu em analisar em que medida a avaliação para as aprendizagens vem orientando as estratégias pedagógicas em uma escola organizada em ciclos no Distrito Federal.

A investigação revelou que ao procurar realizar o diagnóstico das aprendizagens dos estudantes e ao buscar um planejamento articulado das intervenções a serem desenvolvidas a partir das aprendizagens apresentadas, o processo avaliativo, na escola pesquisada, possivelmente, tem colaborado com as estratégias pedagógicas a serem desenvolvidas nos ciclos. Além disso, esta investigação indicou sobre a importância coordenação pedagógica, do planejamento articulado e da atuação do colegiado escolar no e para o desenvolvimento das práticas avaliativas que favoreçam a superação das dificuldades surgidas no decorrer do ensino- aprendizagem.

\section{REFERÊNCIAS}

AGUIAR. Wanda Maria Junqueira; OZELLA, Sergio. Apreensão dos sentidos: aprimoramento dos núcleos de significação. Brasília: Revista Brasileira de Estudos Pedagógicos, v. 94, n. 236, p. 299-322, jan./abr. 2013.

Núcleos de significação como instrumento para a apreensão da

constituição dos sentidos. Brasília: Psicologia: ciência e profissão, v. 26, n. 2, p. 222245 , jun. 2006.

AMBRÓSIO, Ana Cristina da Silva. A recuperação intensiva do ensino fundamental ciclo II: uma análise da prática pedagógica do professor de matemática. Dissertação de Mestrado. Universidade Estadual Paulista - UNESP, 2015. Disponível em: <https://repositorio.unesp.br/handle/11449/149240.>. Acesso em: 10 out. 2018.

ARAÚJO, Ivanildo Amaro de. Educação continuada na escola: traços, trilhas e rumos da coordenação pedagógica. Dissertação de mestrado. Universidade de Brasília - UnB, Brasília, DF, 2000. 
BRASIL. MEC/SEB. Lei de Diretrizes e Bases da Educação Nacional - Lei no 9.394/96. Brasília, 1996. Disponível em:

<http://www.planalto.gov.br/ccivil_03/LEIS/L9394.htm> Acesso em: 11 jul. 2018.

DISTRITO FEDERAL. Diretrizes pedagógicas para organização escolar do $3^{\circ}$ ciclo. Brasília, SEEDF/SUBEB, 2014b.

Diretrizes de Avaliação Educacional: aprendizagem, institucional e em larga escala. Brasília, SUBEB, SUPLAV, 2014d. (Brasil). Secretaria de Estado de Educação. Regimento Escolar da Rede Pública de Ensino do Distrito Federal, 6ª Ed - Brasília, 2015.

DURAN, David. Utilizar pedagogicamente as diferenças entre os alunos: uma prática de tutoria entre iguais. In: FETZNER, Andréa Rosana (Org.). Ciclos em revista: aprendizagem em diálogo com as diferenças. Volume 3. Rio de Janeiro: Ed. WAK. 2008, p.13-32.

GAMBOA, Silvio Sánchez. Pesquisa em educação: métodos e epistemologias. Chapecó: Argos, 2006.

LOCH, Jussara Margareth de Paula. Avaliação de ciclos de formação: teoria e prática. In: Andréa Rosana Fetzner (Org.). Ciclos em Revista - Avaliação: desejos, vozes, diálogos e processos. $4^{\mathrm{a}}$ ed. Rio de Janeiro: Wak, 2008, p. 159-171.

PARO, Victor Henrique. Reprovação escolar: renúncia à educação. São Paulo: Xamã, 2003.

SILVA, Edileuza Fernandes da. O planejamento no contexto escolar: pela qualificação do trabalho docente e discente. In: VILLAS BOAS, B. (Org.). Avaliação: interações com o trabalho pedagógico. Campinas, SP: Papirus, 2017a.

VILLAS BOAS. Benigna M. F. Portfólio, Avaliação e trabalho pedagógico.

Campinas, SP: Papirus, 2012. 